\title{
Ramadan Observance Is Associated with Impaired Kung-Fu-Specific Decision-Making Skills
}

\author{
Anis Saddoud ${ }^{1,2}$, Aïmen Khacharem ${ }^{3,4}$, Cyrine $\mathrm{H}^{\prime}$ Mida ${ }^{1,2}$, Khaled Trabelsi ${ }^{1,2} \mathbb{D}$, Omar Boukhris ${ }^{1,5} \mathbb{D}$, \\ Achraf Ammar 6,7 (D), Cain C. T. Clark ${ }^{8}$ (D) Jordan M. Glenn 9,10 (D), Hamdi Chtourou 1,5 (D), Mohamed Jarraya 1,2,+ \\ Thomas Rosemann ${ }^{11,+}+\mathbb{D}$ and Beat Knechtle ${ }^{11,12, *,+}$
}

Citation: Saddoud, A.; Khacharem, A.; H'Mida, C.; Trabelsi, K.; Boukhris, O.; Ammar, A.; Clark, C.C.T.; Glenn, J.M.; Chtourou, H.; Jarraya, M.; et al. Ramadan Observance Is Associated with Impaired Kung-Fu-Specific Decision-Making Skills. Int. J. Environ Res. Public Health 2021, 18, 7340. https://doi.org/10.3390/ijerph 18147340

Academic Editors: Britton W. Brewer and Jorge Pérez-Gómez

Received: 20 May 2021

Accepted: 2 July 2021

Published: 9 July 2021

Publisher's Note: MDPI stays neutral with regard to jurisdictional claims in published maps and institutional affiliations.

Copyright: (c) 2021 by the authors Licensee MDPI, Basel, Switzerland. This article is an open access article distributed under the terms and conditions of the Creative Commons Attribution (CC BY) license (https:/ / creativecommons.org/licenses/by/ $4.0 /)$.
1 High Institute of Sport and Physical Education of Sfax, University of Sfax, Sfax 3000, Tunisia; anissaddoud75@gmail.com (A.S.); sirinehmida@hotmail.fr (C.H.); trabelsikhaled@gmail.com (K.T.); omarboukhris24@yahoo.com (O.B.); h_chtourou@yahoo.fr (H.C.); jarrayam@yahoo.fr (M.J.)

2 Research Laboratory: Education, Motricity, Sport and Health, EM2S, LR19JS01, University of Sfax, Sfax 3000, Tunisia

3 UFR SESS-STAPS, Paris-East Créteil University, LIRTES (EA 7313), 94000 Créteil, France; aimen.khacharem@gmail.com

4 DeVisu (EA 2445), Polytechnic University of Hauts-de-France, 59313 Valenciennes, France

5 Physical Activity, Sport, and Health, UR18JS01, National Observatory of Sport, Tunis 1003, Tunisia

6 Institute of Sport Science, Otto-von-Guericke University, 39106 Magdeburg, Germany; ammar.achraf@ymail.com

7 Interdisciplinary Laboratory in Neurosciences, Physiology and Psychology: Physical Activity, Health and Learning (LINP2), UFR STAPS, UPL, Paris Nanterre University, 92000 Nanterre, France

8 Centre for Intelligent Healthcare, Coventry University, Coventry CV1 5FB, UK; ad0183@coventry.ac.uk

9 Department of Health, Exercise Science Research Center, Human Performance and Recreation, University of Arkansas, Fayetteville, AR 72701, USA; jordan.mckenzie.glenn@gmail.com

10 Neurotrack Technologies, 399 Bradford St, Redwood City, CA 94063, USA

11 Institute of Primary Care, University of Zurich, 8006 Zurich, Switzerland; thomas.rosemann@usz.ch

12 Medbase St. Gallen Am Vadianplatz, 9000 St. Gallen, Switzerland

* Correspondence: beat.knechtle@hispeed.ch

$+\quad$ These authors contributed equally to this work.

Abstract: The aim of the present study is to evaluate the effect of Ramadan observance (RAM) on decision-making in Kung-Fu athletes. Fourteen male Kung-Fu athletes (mean age $=19 \pm 3$ years) completed two test sessions: before Ramadan (BR) and at the end of Ramadan (ER). In the afternoon of each session (between 16:00 h and 18:00 h), participants completed: Epworth Sleepiness Scale (ESS), Profile of Mood States (POMS), and Pittsburg Sleep Quality Index (PSQI). Subjects also reported subjective fatigue, alertness, and concentration. Additionally, all participants performed video-based decision-making tasks (i.e., reaction time and decision-making). Results indicated that reaction time decreased by $30 \%$ at ER vs. BR $(p<0.01)$. However, decision-making decreased by $9.5 \%$ at ER vs. BR $(p<0.05)$. PSQI results indicated sleep quality score, sleep duration, and sleep efficiency were negatively affected at ER compared to BR $(p<0.05)$. ESS was higher at ER compared to BR $(p<0.05)$. In addition, fatigue scores, estimated by the POMS and current subjective feelings (i.e., fatigue, concentration, and alertness), were also negatively affected at ER compared to BR $(p<0.05)$. In conclusion, Ramadan observance was associated with an adverse effect on sleep and decision making, as well as feelings of fatigue, alertness, and concentration.

Keywords: intermittent fasting; decision making; sleep; sleepiness; fatigue; athletes

\section{Introduction}

Every year, Muslims abstain from eating, drinking, and sexual intercourse, from sunrise to sunset, over a period that lasts 29 or 30 days, i.e., the month of Ramadan [1]. Ramadan observance (RAM) has been reported to yield important negative changes in physical performance [2,3], body composition [4], and eating habits [5,6]. Moreover, 
the continuance of training during RAM (often scheduled at night), in association with nocturnal mealtimes [7], could also affect negatively sleep-wake patterns [8,9]. Additionally, some studies have shown increased fatigue estimated by the Profile of Mood State (POMS) scale (without any changes in tension, depression, anger, confusion, and vigor estimated by the POMS) [10-12], by the Hooper questionnaire [13,14] and by the rating of perceived exertion [15].

However, despite the evidence in the extant literature demonstrating that cognitive performance may be impaired by the typical changes related to meal timing and macronutrient composition [16,17], dehydration [18,19], and sleep loss [20,21], a dearth of attention has been dedicated to understanding the effect of RAM on cognitive function in athletes [9,22]. For example, Tian et al. [22] evaluated the effect of RAM on cognitive function using computerized neuropsychological testing, according to time of day in healthy Muslim athletes, and reported that in the morning $(09: 00 \mathrm{~h})$, detection and identification performances were better during RAM vs. after RAM while in the afternoon (16:00 h), verbal learning and short-term memory performances were better after RAM compared to during RAM [22]. These findings indicate that the effects of RAM on cognitive function were heterogeneous and domain-specific with respect to the time of day [22]. Conversely, Chamari et al. [9] showed that RAM did not affect cognitive performance in trained cyclists from the Middle East.

To date, to the authors' knowledge, no published research has examined the effects of RAM on sport-specific decision-making, which is a vital aspect of perceptual skill. Moreover, in combat sports, the ability to perceive and process opponent intention is important for evasion, to initiate an effective counter-attack [23]. Indeed, in such sports, the time for making decisions is a condition that should always be considered, given that actions often take place within highly complex and time-constrained situations [24].

Therefore, the aim of this study was to evaluate the effect of RAM on decision-making tasks, as well as sleep, sleepiness, mood states, and feelings of fatigue in combat sports. In the present study, Kung-Fu was chosen because of its dynamic nature, where adaptation and decision making are characteristics [23]. Given that RAM is generally accompanied by a myriad of changes (e.g., meal timing, dehydration, sleep loss, mood, reaction time, and cognitive performance), we hypothesized that the decision-making performance (decision time and decision accuracy) of Kung-Fu athletes would be negatively affected during RAM compared to the pre-RAM period. Additionally, we hypothesized that RAM would be associated with a decline in sleep quality and the mood state of Kung-Fu athletes.

\section{Materials and Methods}

\subsection{Participants}

Fourteen male Kung-Fu athletes (mean age $=19 \pm 3$ years) volunteered for this study with experience ranging between 3 and 6 years. Eight of them had a black belt and the remaining had a brown belt. They participated in regional and national high-level competitions.

After receiving a description of the protocol, potential risks, and benefits of the study, participants gave their written consent to participate in this investigation. The study was conducted according to the declaration of Helsinki and the protocol was fully approved by the Research Ethics Committee before the commencement of the assessments. The study was carried out in Tunisia, when Ramadan started on the 5 May and concluded on the 3 June 2019. The length of each fasting day during Ramadan observance was approximately $\sim 16 \mathrm{~h}$. The criteria for participant inclusion in this study were as follows: all participants (I) continued training during Ramadan, (II) were non-smokers, (III) did not have pathological sleep disorders, and (VI) did not consume alcohol.

\subsection{Material and Apparatus}

For the video stimuli, a Kung-Fu fight that opposed of two male athletes (red and blue) was recorded by a digital video camera (Sony DCR_TRV10). The recording took place in a 
judo-exercise gymnasium, where the video camera was positioned at the height of $1.7 \mathrm{~m}$ and at a distance of $5 \mathrm{~m}$ from the athletes' initial position. From the recording of the entire fight, 35 scenarios were chosen (with the collaboration of two Kung-Fu expert coachesmean age $=45 \mathrm{yrs}$ ) as the stimuli to be presented in the experimental condition. During the experiment, each fight scenario lasted between 4 and $10 \mathrm{~s}$ and was then automatically occluded by a black frame at the moment two other expert coaches (mean age $=44$ years) considered it appropriate for a decision to be made. Participants were asked to verbally indicate, as quickly as possible, "What offensive action should the athlete with the RED uniform do at that moment?". The options were: (a) upper kick, (b) middle kick, or (c) lower kick.

The experimental test was performed indoors, without external interference. All the scenarios were displayed on a white wall to create a large $4 \mathrm{~m} \times 3 \mathrm{~m}$ projected image using a Sanyo PDG-DET100L Projector (Sanyo 231 Electric CoLtd., Osaka, Japan). The participants were positioned three meters from the screen and seated with a clear view of the screen. Players were introduced to five practical scenarios prior to the test for familiarization.

\subsection{Experimental Design}

A familiarization session was performed before Ramadan. Participants conducted two test sessions: before two weeks of Ramadan (BR) and at the end of the last week of Ramadan (i.e., the 28th day of Ramadan) (ER). In the afternoon of each session (between 16:00 $\mathrm{h}$ and 18:00 h), participants completed the Epworth Sleepiness Scale (ESS) [25], followed by the POMS [26] and the Pittsburg Sleep Quality Index (PSQI) [27] questionnaires. In addition, participants rated their current subjective feelings for their levels of 'fatigue', 'alertness', and 'concentration' on a $100 \mathrm{~mm}$ visual analogue scale [28]. Finally, the participants performed a decision test (Figure 1).

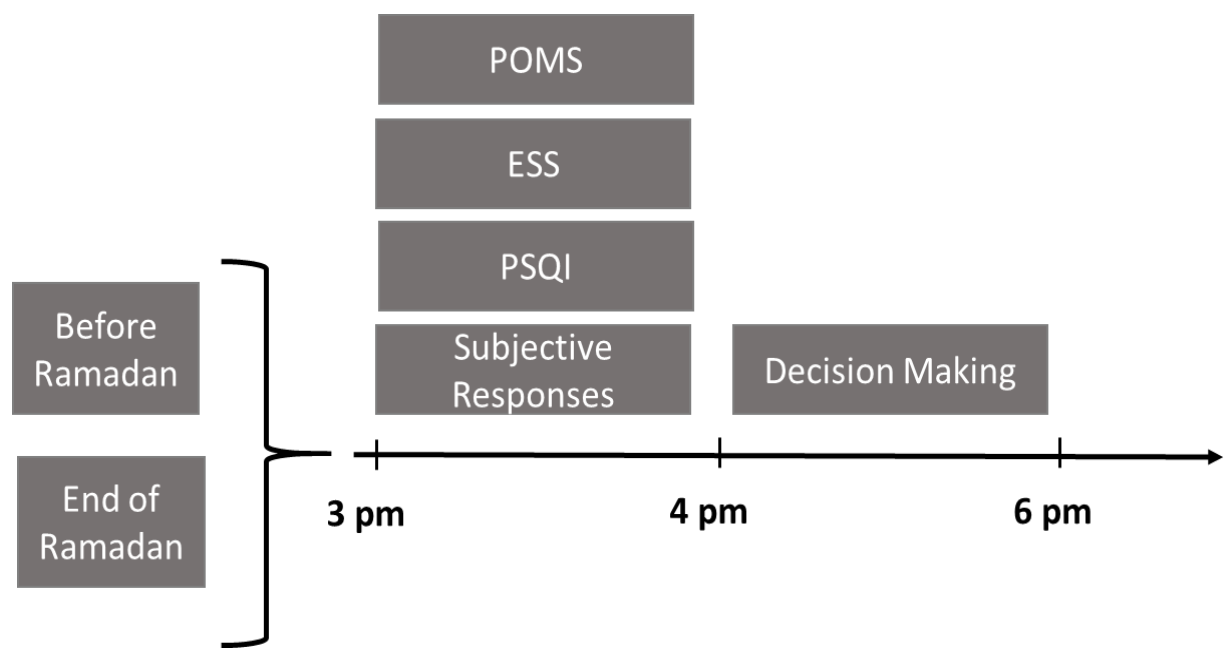

Figure 1. The schematic representation of the experimental design.

\subsection{Procedure}

Each participant was invited to follow the video sequences presented via a video projector. Five sequences were utilized during the familiarization session. The remaining sequences $(n=30)$ were used to evaluate the athletes' decision making.

After the onset of an offensive action, and simultaneously when the video was stopped, participants were asked to determine if the action was orientated on the upper, the middle, or the lower body part of the athlete. Each participant was asked to decide as quickly and as accurately as possible the best response by clicking on the keyboard (three keys for the three possible solutions) of the computer. The decision time and accuracy were automatically recorded using $\mathrm{C \#}$ programming language. 


\subsection{The Profile of Mood States (POMS)}

Subjective mood states were assessed using the French version of the POMS questionnaire [26]. This is a self-report questionnaire consisting of 65 adjectives designed to evaluate six states (i.e., tension, depression, anger, vigor, fatigue, and confusion). Responses to each item range from 0 to 4 , with higher scores indicating a more negative mood ( 0 indicates "Not at all" and 4 indicates "Extremely"). The total score of the POMS was calculated as follows: total score $=($ tension + depression + anger + fatigue + confusion $)$-vigor.

\subsection{The Epworth Sleepiness Scale (ESS)}

This ESS questionnaire was used to assess subjective sleepiness [25]. The participant responded how likely they are to doze in eight different daily situations on a 4-point scale. ESS scores were interpreted based on the following references [29]: 0-5 indicates lower than normal daytime sleepiness, 6-10 indicates higher than normal daytime sleepiness, 11-12 indicates mild excessive daytime sleepiness (EDS), 13-15 indicates moderate EDS, and 16-24 indicates severe EDS.

\subsection{The Pittsburg Sleep Quality Index (PSQI)}

The sleep quality was assessed by the PSQI [30], which has been extensively validated in different cultures and populations [31]. The Arabic-validated version of the PSQI was utilized in the present study [27]. The PSQI questionnaire was used to assess subjective sleep quality over the previous month (i.e., one-month BR and during the month of Ramadan). The questionnaire was composed of 19 questions, each representing one of the seven components of sleep quality: subjective sleep quality, sleep latency, sleep duration, sleep efficiency, sleep disturbance, sleep medication intake, and daytime dysfunction. Each component score was rated on a 3-point scale, leading to a sum of up to 21 points. PSQI scores $>5$ and $\leq 5$ indicated, respectively, poor and good sleep qualities [30].

\subsection{Perceptual Measures}

Participants rated their subjective feelings before the test session to estimate the level of attention, concentration, and fatigue using a $100 \mathrm{~mm}$ visual analogue scale. The participant marked the point that signified his perception of his current state for each question. The visual analogue scale score was determined by measuring the distance in millimeters ( $\mathrm{mm}$ ), from the left side of the end of the line to the player's marked line. In addition, the sleep duration of the night preceding the test session, during the two periods of the study (i.e., BR and ER), was estimated by each participant. Furthermore, participants were also asked about their subjective sleep quality for each night preceding the test session using a scale ranging from " 1 " (very poor quality) to " 5 " (very good quality).

\subsection{Statistical Analysis}

All statistical tests were processed using STATISTICA Software (StatSoft, Paris, France). Mean and SD (standard deviation) values were calculated for each variable.

The software G*Power [32] was used, as well as a priori to calculate the necessary minimum sample size, based on procedures suggested by Beck [33]. Values for $\alpha$ were set at 0.05 and for power at 0.8. Based on an earlier study by Boukhris et al. [15] and discussions between the authors, the likely effect sizes were estimated as 0.45 . In total, to reach the desired power, for a pre- vs. post-repeated measures study design, data from at least twelve participants were deemed to be sufficient to minimize the risk of incurring a type 2 statistical error.

The Shapiro-Wilk test revealed that sleep latency, total score of PSQI, mood states (i.e., tension, anger, vigor, fatigue, and confusion), ESS, decision test, fatigue, and concentration were normally distributed and were analyzed using a paired sample t-test in order to compare them between BR and ER. However, when the Shapiro-Wilk test was significant $(p<0.05)$, pairwise comparisons were conducted using a Wilcoxon test. The statistical calculation was performed for a two-tailed test. Effect size was calculated using Cohen's d 
for all parameters. Cohen's d of 0.2, 0.5, and 0.8 represent small, moderate, and large effect sizes, respectively [34]. Statistical significance was accepted, for all analyses, at the level of $p<0.05$.

\section{Results}

\subsection{Profile of Mood States (POMS)}

The results of the POMS are illustrated in Table 1. There was no significant difference between BR and ER for anxiety, confusion, depression, tension, vigor, and total score. However, statistical analysis showed that fatigue increased at ER vs. BR.

Table 1. The results of the Profile of Mood States recorded before (BR) and at the end of Ramadan (ER).

\begin{tabular}{ccccccc}
\hline Variables & BR & ER & Test & $\boldsymbol{p}$-Value & Cohen's $\boldsymbol{d}$ & $\mathbf{9 5 \%}$ IC \\
\hline Tension (A.U) & $9 \pm 4$ & $8 \pm 4$ & $\mathrm{~T}=0.80$ & 0.4 & 0.25 (moderate effect) & $-1.31-2.88$ \\
Depression (A.U) & $7 \pm 7$ & $6 \pm 5$ & $\mathrm{Z}=0.44$ & 0.6 & 0.16 (small effect) & $-2.48-4.48$ \\
Anger (A.U) & $9 \pm 6$ & $10 \pm 5$ & $\mathrm{~T}=-0.56$ & 0.5 & 0.18 (small effect) & $-4.10-2.39$ \\
Vigor (A.U) & $19 \pm 4$ & $18 \pm 6$ & $\mathrm{~T}=1.07$ & 0.3 & 0.19 (small effect) & $-1.43-4.29$ \\
Fatigue (A.U) & $5 \pm 4$ & $8 \pm 5^{*}$ & $\mathrm{~T}=-2.52$ & 0.02 & 0.66 (large effect) & $-5.56--0.43$ \\
Confusion (A.U) & $7 \pm 4$ & $7 \pm 4$ & $\mathrm{~T}=0.42$ & 0.6 & 0.04 (small effect) & $-0.87-1.30$ \\
Total score (A.U) & $18 \pm 24$ & $23 \pm 21$ & $\mathrm{~T}=-1.17$ & 0.2 & 0.22 (moderate effect) & $-14.37-4.22$ \\
\hline
\end{tabular}

*: significant difference compared to BR; A.U: arbitrary unit.

\subsection{Epworth Sleepiness Scale (ESS)}

Statistical analysis showed that ESS increased significantly from $5.6 \pm 2.9$ at BR to $7.1 \pm 3.5$ at $\operatorname{ER}(21 \%, p=0.004$, and $d=0.46)$.

\subsection{The Pittsburgh Sleep Quality Index (PSQI)}

The results of the PSQI questionnaire are presented in Table 2. Sleep quality scores were higher during RAM compared to BR. However, sleep duration and sleep efficiency were lower during RAM compared to BR.

There was no significant difference between BR and during RAM for sleep latency ( $p=0.14, d=0.45$ ), sleep disturbance, daytime dysfunction, the use of sleeping medications, and total PSQI.

Table 2. Sleep parameters recorded by the PSQI questionnaire before Ramadan (BR) and at the end of Ramadan (ER).

\begin{tabular}{ccccccc}
\hline Variables & BR & ER & Test & $p$-Value & Cohen's $d$ & 95\% IC \\
\hline Sleep quality (A.U) & $1.1 \pm 0.9$ & $1.9 \pm 0.9^{*}$ & $\mathrm{Z}=2.34$ & 0.01 & 0.88 (large effect) & $-1.19--0.23$ \\
Sleep latency (min) & $14.6 \pm 9.0$ & $19.1 \pm 10.6$ & $\mathrm{~T}=-1.56$ & 0.14 & 0.45 (moderate effect) & $-10.70-1.70$ \\
Sleep duration (h) & $7.8 \pm 1.1$ & $6.3 \pm 1.9^{*}$ & $\mathrm{Z}=2.41$ & 0.01 & 1.26 (large effect) & $0.42-2.64$ \\
Sleep efficiency (\%) & $97.1 \pm 5.0$ & $87.2 \pm 13.0^{*}$ & $\mathrm{Z}=2.08$ & 0.03 & 1.01 (large effect) & $1.25-18.60$ \\
Sleep disturbances (A.U) & $1.2 \pm 0.4$ & $1.1 \pm 0.9^{*}$ & $\mathrm{Z}=0.36$ & 0.7 & 0.14 (small effect) & $-0.35-0.49$ \\
Daytime dysfunction (A.U) & $1.1 \pm 1.3$ & $0.9 \pm 0.9$ & $\mathrm{Z}=1.34$ & 0.1 & 0.17 (small effect) & $-0.13-0.70$ \\
The use of sleeping & $0 \pm 0$ & $0 \pm 0$ & - & - & - & - \\
medications (A.U) & $5.2 \pm 2.4$ & $6.4 \pm 2.9$ & $\mathrm{~T}=-1.70$ & 0.1 & 0.45 (moderate effect) & $-2.75-0.32$ \\
Total score of PSQI (A.U) & $5.2 \pm$
\end{tabular}

*: Significant difference in comparison with BR; A.U: arbitrary unit.

\subsection{Perceptual Measures}

The obtained results of the subjective responses are provided in Table 3. Compared to BR, sleep duration, sleep quality, attention, and concentration decreased significantly at ER. However, fatigue increased significantly at ER compared to BR. 
Table 3. The perceived levels of subjective attention, fatigue, sleep duration, sleep quality, and concentration recorded before Ramadan (BR) and at the end of Ramadan (ER).

\begin{tabular}{ccccccc}
\hline Variables & BR & ER & Test & $p$-Value & Cohen's $\boldsymbol{d}$ & 95\% IC \\
\hline Sleep duration (h) & $7.3 \pm 1.2$ & $6.1 \pm 1.8^{*}$ & $\mathrm{Z}=2.13$ & 0.03 & 0.78 (large effect) & $0.004-0.09$ \\
Sleep quality (A.U) & $3.7 \pm 0.9$ & $2.6 \pm 1.2^{*}$ & $\mathrm{Z}=2.40$ & 0.01 & 1.03 (large effect) & $0.30-1.83$ \\
Attention (A.U) & $73.9 \pm 20.8$ & $47.5 \pm 19.3^{*}$ & $\mathrm{Z}=2.62$ & 0.008 & 1.31 (large effect) & $8.40-44.45$ \\
Concentration (A.U) & $75.4 \pm 16.7$ & $53.9 \pm 18.6^{*}$ & $\mathrm{~T}=2.84$ & 0.01 & 1.21 (large effect) & $5.15-37.69$ \\
Fatigue (A.U) & $38.6 \pm 25.3$ & $60.4 \pm 24.9 *$ & $\mathrm{~T}=-2.58$ & 0.02 & 0.86 (large effect) & $-39.99--3.57$ \\
\hline
\end{tabular}

*: Significant difference in comparison with BR; A.U: arbitrary unit.

\subsection{Decision-Making: Response Accuracy and Reaction Time}

As illustrated in Figure 2, statistical analysis showed that the response accuracy significantly decreased from BR to ER $(20.0 \pm 2.4$ vs. $18.1 \pm 3.0 ; p=0.02, d=0.69$, and $95 \%$ IC $=0.21-3.50)$.

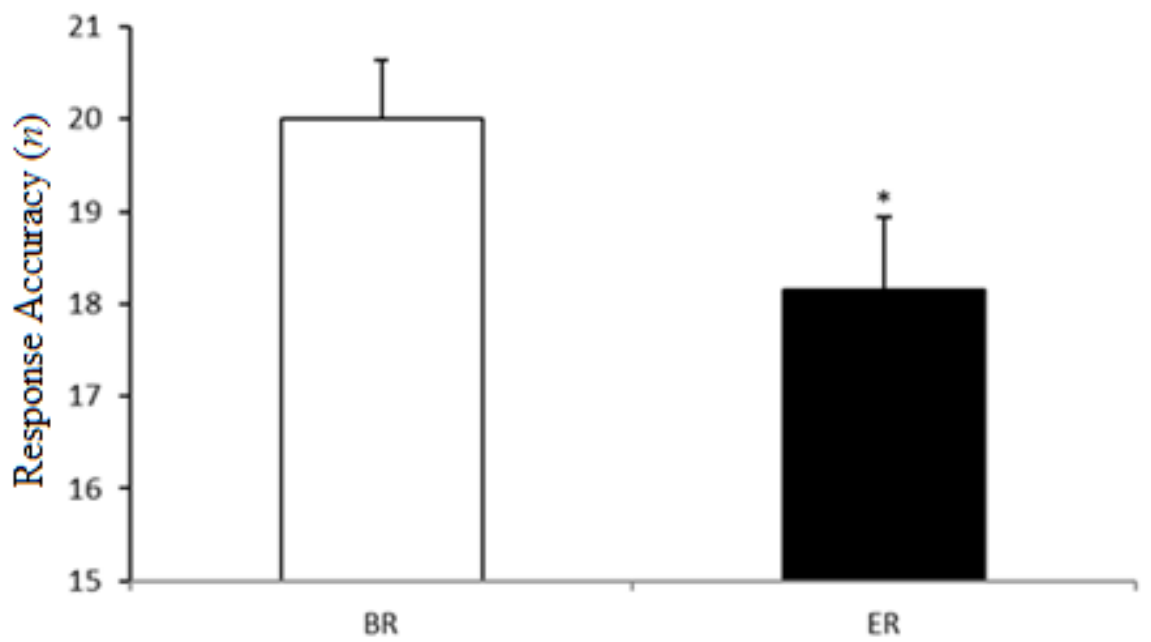

Figure 2. The response accuracy recorded before Ramadan (BR) and at the end of Ramadan (ER). *: Significant difference compared to BR.

Statistical analysis showed that reaction time significantly decreased at ER compared to BR ( $1.0 \pm 0.4$ vs. $0.7 \pm 0.3 ; p=0.002, d=0.84$, and 95\% IC $=0.09-0.33)$ (Figure 3$)$.

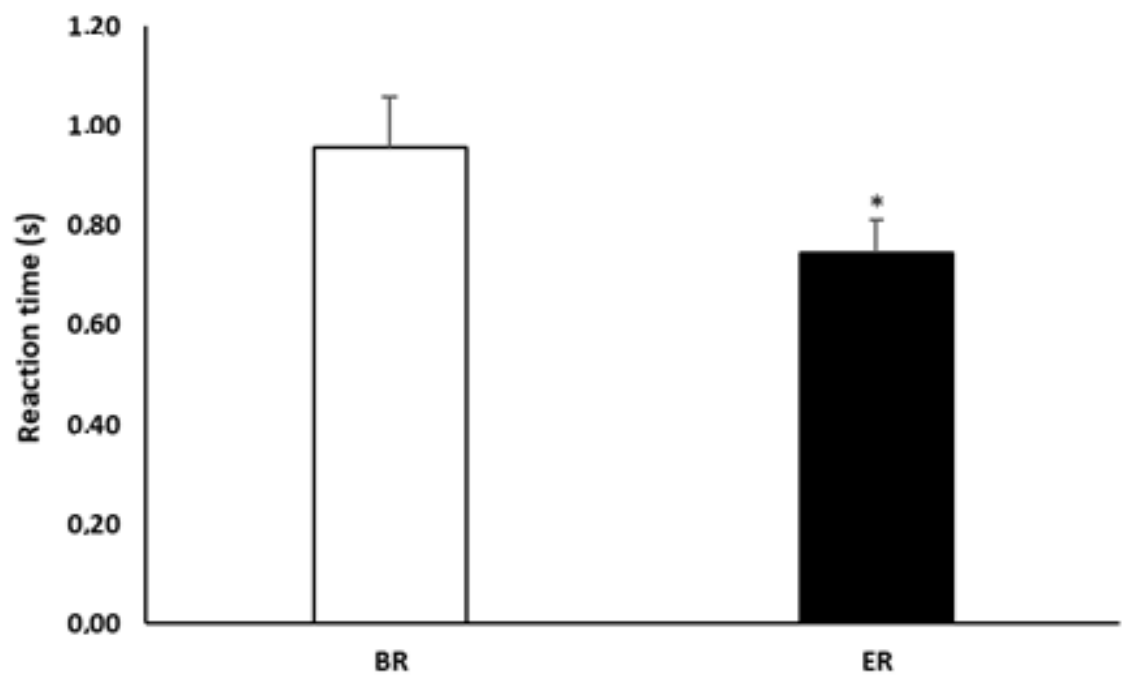

Figure 3. Reaction time recorded before Ramadan (BR) and at the end of Ramadan (ER). *: Significant difference compared to BR. 


\section{Discussion}

The purpose of the present study was to evaluate the difference between BR and ER on decision making (i.e., decision accuracy and time) as well as on sleep, sleepiness, mood states, and feelings of fatigue in Kung-Fu athletes. The present results showed that athletes' decision-making (i.e., response accuracy and reaction time) BR was better than at the ER. Similarly, Cherif et al. [35] reported that daylight fasting could negatively affect many aspects of physical performance and mental health, including coping and decision-making strategies. Thus, the cognitive and physical aspects of RAM can represent a notable challenge for Muslim athletes during Ramadan [35]. In this context, the literature has demonstrated that alertness, memory, reaction time, and psychomotor performance may be deleteriously affected by RAM [14,36-39]. However, the present findings were not in agreement with previous data, showing that cognitive function was unaffected by RAM $[9,40,41]$.

Sleep disruption is among the many factors that could negatively affect the decisionmaking of athletes during RAM. Indeed, Venkatraman et al. [42] suggested that decisionmaking was altered by sleep loss, which modulates activation in the nucleus accumbens and insula brain regions, related to risky decision making and emotional processing. In accordance with previous studies $[1,8,13,43,44]$, sleep duration during the night before the test was less during vs. BR. Similarly, the average sleep duration at BR (reported by the PSQI) was higher than during RAM. This sleep loss may be attributed to the shift of training and meal timing during the night of RAM, which could lead to 1-2 $\mathrm{h}$ of sleep loss per day $[45,46]$. Additionally, this sleep loss could be the cause of an increase of daytime sleepiness $[8,46]$. Indeed, the current study demonstrated that daytime sleepiness was increased at ER vs. BR. However, this increase of sleepiness level indicates higher normal daytime sleepiness; thus, sleepiness was likely not a factor that contributed to the alteration of decision-making during RAM [47]. Indeed, the alteration of decisionmaking during RAM could be attributed to sleep loss [21]. In support of this claim, it has been reported that sleep deprivation leads to a slowing of reaction times and attentional deficits, particularly in the late afternoon [14]. Additionally, it has been reported that an impairment of sleep could affect the fatigue and supercompensation response in welltrained athletes [21]. Furthermore, sleeping less than the recommended duration (i.e., 9-10 h/day [48] or $8 \mathrm{~h} /$ day [49]) could provoke deficits in cognitive function [14]. In fact, the participants in the present study slept $\sim 6.3 \mathrm{~h}$ during RAM, which is less than the recommended duration of sleep. However, other studies reported that when sleep duration was unchanged during RAM, cognitive performance was unaffected $[9,41]$. When the sleep disruptions persist throughout RAM, mood swings and a higher feeling of fatigue are often reported [50], thus negatively affecting afternoon performance in many sports activities. In the present study, RAM was associated with negative changes in fatigue (estimated by the POMS questionnaire), attention, and concentration. Concordant with the present results, some previous studies have reported increased subjective ratings of fatigue via the POMS $[11,12]$ and the Hooper questionnaire $[13,14]$. Therefore, the alteration of decision-making apparent during RAM could be attributed to the decreased attention and concentration, as well as increased feelings of fatigue, possibly due to sleep disruptions. However, in the present study, the decrease of the decision time at the ER in comparison with BR was not accompanied with an improvement in decision making.

In accord with the aim of this study, to evaluate the effect of RAM on decisionmaking in Kung-Fu athletes, we have presented a novel addition to the literature that helps to elucidate the impact of Ramadan on combat sports athletes. Indeed, this represents the principal strength of the study and provides a stepping stone for researchers and practitioners to further examine the RAM phenomenon. Despite the novelty of our study, there are some limitations that warrant consideration. Indeed, the principal limitation is that the present study is observational, and thus, no causal inferences can be made. Next, the lack of objective sleep measurement may have resulted in some underestimation in our study. Moreover, despite the advantages of using video for exploring decision-making and 
perceptual expertise in sports, this tool suffers from its inability to faithfully reproduce the environment of athletes in performance situations [51]. In addition, athletes often react to the video from the moment a visual stimulus is presented, while a natural environment offers multiple sources of information including visual, auditory, or kinesthetic [52]. As the participants of the present study were Arabic native speakers, and as to the best of our knowledge no previous study has validated the POMS in the Arabic language, another limitation for the current study was the utilization of the French version of the POMS. However, all participants were students and the French language is taught from the third primary year to university level. Therefore, we are confident that all participants satisfactorily understood the French version of the POMS questionnaire. The results of the present study could not be generalized to all populations. In fact, our data and conclusions only refer to the male population, thus highlighting the need for further work specific to females. Additionally, the time of day could influence performance, attention, and fatigue according to an athlete's circadian preferences [53-55]. Furthermore, there is no control for scheduled times of sleeping habits, eating, meal composition, training load, and training. This is difficult to altogether achieve during Ramadan, but future studies should at least control the training load during Ramadan. Finally, the present study was not powered to discern the categorized differences between athletes, BR vs. ER. We therefore advocate that future, suitably powered, trials seek to discern differences across the categories of sleep, sleepiness, mood states, feelings of fatigue, and Kung-Fu specific decision-making skills.

\section{Conclusions}

The present study demonstrated that RAM was associated with reductions in decision making. The alteration of decision-making during RAM could be attributed to a reduced attention and concentration, as well as increased feelings of fatigue, which in turn were likely influenced by sleep disruptions. Further work, particularly experimental study designs, are warranted to more firmly elucidate the impact of fasting on sleep, sleepiness, mood states, feelings of fatigue, and Kung-Fu specific decision-making skills.

Author Contributions: Conceptualization, A.S., A.K. and M.J.; methodology, A.S., A.K. and M.J.; software, A.S., A.K., C.H., K.T., O.B. and M.J.; validation, A.S., A.K., C.H., K.T., O.B., A.A., C.C.T.C., J.M.G., H.C., M.J., T.R. and B.K.; formal analysis, A.S., A.K. and O.B.; investigation, A.S. and O.B.; resources, A.S., A.K. and M.J.; data curation, A.S., A.K., K.T., O.B. and M.J.; writing-original draft preparation, A.S., C.H., O.B. and H.C.; writing-review and editing, A.K., K.T., A.A., C.C.T.C., J.M.G., M.J., T.R. and B.K.; visualization, A.S., A.K., C.H., K.T., O.B. and M.J.; validation, A.S., A.K., C.H., K.T., O.B., A.A., C.C.T.C., J.M.G., H.C., M.J., T.R. and B.K.; supervision, A.K. and M.J.; project administration, A.S., A.K., K.T., O.B., A.A., H.C. and M.J.; funding acquisition, A.S. and O.B. All authors have read and agreed to the published version of the manuscript.

Funding: This research received no external funding.

Institutional Review Board Statement: The study was conducted according to the guidelines of the Declaration of Helsinki and approved by the Research Ethics Committee.

Informed Consent Statement: Informed consent was obtained from all participants involved in the study.

Data Availability Statement: The data that support the findings of this study are available on request from the first author, Anis Saddoud.

Conflicts of Interest: The authors declare no conflict of interest.

\section{References}

1. Chtourou, H. Effects of Ramadan Fasting on Health and Athletic Performance; Omics Group International: New York, NY, USA, 2015; pp. 6-14. Available online: https:// www.esciencecentral.org/ebooks/ebookdetail/effects-of-ramadan-fasting-on-healthandathletic-performance (accessed on 7 July 2014). [CrossRef]

2. Chtourou, H.; Trabelsi, K.; Boukhris, O.; Ammar, A.; Shephard, R.J.; Bragazzi, N.L. Effects of Ramadan fasting on physical performances in soccer players: A systematic review. Tun. Med. 2019, 97, 1114-1131. 
3. Abaïdia, A.E.; Daab, W.; Bouzid, M.A. Effects of Ramadan fasting on physical performance: A systematic review with metaanalysis. Sports Med. 2020, 50, 1009-1026. [CrossRef] [PubMed]

4. Aloui, A.; Baklouti, H.; Souissi, N.; Chtourou, H. Effects of Ramadan fasting on body composition in athletes: A systematic review Effets du jeûne du Ramadan sur la composition corporelle des sportifs: Revue systématique. Tun. Med. 2019, 97, 1087-1094.

5. Chtourou, H.; Chtourou, L.; Trabelsi, K.; Tahri, N.; Souissi, N. Possible gastrointestinal disorders for athletes during Ramadan: An overview. Biol. Rhythm Res. 2018, 49, 51-60. [CrossRef]

6. Boukhris, O.; Hsouna, H.; Chtourou, L.; Abdesalem, R.; BenSalem, S.; Tahri, N.; Trabelsi, K.; Stannard, S.R.; Chtourou, H. Effect of Ramadan fasting on feelings, dietary intake, rating of perceived exertion and repeated high intensity short-term maximal performance. Chronobiol. Int. 2019, 36, 1-10. [CrossRef]

7. Trabelsi, K.; Ammar, A.; Zlitni, S.; Boukhris, O.; Khacharem, A.; El-Abed, K.; Khanfir, S.; Shephard, R.J.; Stannard, S.R.; Bragazzi, N.L.; et al. Practical recommendations to improve sleep during Ramadan observance in healthy practitioners of physical activity. Tun. Med. 2019, 97, 1077-1086.

8. Trabelsi, K.; Bragazzi, N.; Zlitni, S.; Khacharem, A.; Boukhris, O.; El-Abed, K.; Ammar, A.; Khanfir, S.; Shephard, R.J.; Hakim, A.; et al. Observing Ramadan and sleep-wake patterns in athletes: A systematic review, meta-analysis and meta-regression. Br. J. Sports Med. 2019, 54, 674-680. [CrossRef]

9. Chamari, K.; Briki, W.; Farooq, A.; Patrick, T.; Belfekih, T.; Herrera, C.P. Impact of Ramadan intermittent fasting on cognitive function in trained cyclists: A pilot study. Biol. Sport 2016, 33, 49. [CrossRef] [PubMed]

10. Chennaoui, M.; Desgorces, F.; Drogou, C.; Boudjemaa, B.; Tomaszewski, A.; Depiesse, F.; Burnat, P.; Chalabi, H.; Gomez-Merino, D. Effects of Ramadan fasting on physical performance and metabolic, hormonal, and inflammatory parameters in middle-distance runners. Appl. Physiol. Nutr. Metab. 2009, 34, 587-594. [CrossRef]

11. Chtourou, H.; Hammouda, O.; Souissi, H.; Chamari, K.; Chaouachi, A.; Souissi, N. The effect of Ramadan fasting on physical performances, mood state and perceived exertion in young footballers. Asian J. Sports Med. 2011, 2, 177. [CrossRef] [PubMed]

12. Chtourou, H.; Hammouda, O.; Chaouachi, A.; Chamari, K.; Souissi, N. The effect of time-of-day and Ramadan fasting on anaerobic performances. Int. J. Sports Med. 2012, 33, 142-147. [CrossRef] [PubMed]

13. Baklouti, H.; Rejeb, N.; Aloui, A.; Jaafar, H.; Ammar, A.; Chtourou, H.; Girard, O.; Souissi, N. Short versus long small-sided game training during Ramadan in soccer players. Phys. Ther. Sport 2017, 24, 20-25. [CrossRef] [PubMed]

14. Boukhris, O.; Trabelsi, K.; Shephard, R.J.; Hsouna, H.; Abdessalem, R.; Chtourou, L.; Ammar, A.; Braggazi, N.L.; Chtourou, H. Sleep patterns, alertness, dietary intake, muscle soreness, fatigue, and mental stress recorded before, during and after Ramadan observance. Sports 2019, 7, 118. [CrossRef]

15. Chaouachi, A.; Coutts, A.J.; Chamari, K.; Wong, D.P.; Chaouachi, M.; Chtara, M.; Roky, R.; Amri, M. Effect of Ramadan intermittent fasting on aerobic and anaerobic performance and perception of fatigue in male elite judo athletes. J. Strength Cond. Res. 2009, 23, 2702-2709. [CrossRef]

16. Dye, L.; Lluch, A.; Blundell, J.E. Macronutrients and mental performance. Nutrition 2000, 16, 1021-1034. [CrossRef]

17. Gibson, E.L.; Green, M.W. Nutritional influences on cognitive function: Mechanisms of susceptibility. Nutr. Res. Rev. 2002, 15, 169-206. [CrossRef]

18. McCartney, D.; Desbrow, B.; Irwin, C. The effect of fluid intake following dehydration on subsequent athletic and cognitive performance: A systematic review and meta-analysis. Sports Med. Open 2017, 3, 13. [CrossRef]

19. Fortes, L.S.; Nascimento-Júnior, J.R.; Mortatti, A.L.; Lima-Júnior, D.R.A.A.D.; Ferreira, M.E. Effect of dehydration on passing decision making in soccer athletes. Res. Q. Exerc. Sport 2018, 89, 332-339. [CrossRef]

20. Taheri, M.; Arabameri, E. The effect of sleep deprivation on choice reaction time and anaerobic power of college student athletes. Asian J. Sports Med. 2012, 3, 15. [CrossRef] [PubMed]

21. Fullagar, H.H.; Skorski, S.; Duffield, R.; Hammes, D.; Coutts, A.J.; Meyer, T. Sleep and athletic performance: The effects of sleep loss on exercise performance, and physiological and cognitive responses to exercise. Sports Med. 2015, 45, 161-186. [CrossRef]

22. Tian, H.H.; Aziz, A.R.; Png, W.; Wahid, M.F.; Yeo, D.; Png, A.L.C. Effects of fasting during Ramadan month on cognitive function in Muslim athletes. Asian J. Sports Med. 2011, 2, 145. [CrossRef]

23. Ottoboni, G.; Russo, G.; Tessari, A. What boxing-related stimuli reveal about response behaviour. J. Sports Sci. 2015, 33, 1019-1027. [CrossRef]

24. Russo, G.; Ottoboni, G. The perceptual-Cognitive skills of combat sports athletes: A systematic review. Psychol. Sport Exerc. 2019, 44, 60-78. [CrossRef]

25. Ahmed, A.E.; Fatani, A.; Al-Harbi, A.; Al-Shimemeri, A.; Ali, Y.Z.; Baharoon, S.; Al-Jahdali, H. Validation of the Arabic version of the Epworth sleepiness scale. J. Epidemiol. Glob. Health 2014, 4, 297-302. [CrossRef] [PubMed]

26. Cayrou, S.; Dickès, P.; Dolbeault, S. Version française du profile of mood states (POMS-f). J. Ther. Comport. Cogn. 2003, 13, 83-88.

27. Suleiman, K.H.; Yates, B.C.; Berger, A.M.; Pozehl, B.; Meza, J. Translating the Pittsburgh sleep quality index into Arabic. West. J. Nurs. Res. 2010, 32, 250-268. [CrossRef]

28. Aziz, A.R.; Wahid, M.F.; Png, W.; Jesuvadian, C.V. Effects of Ramadan fasting on 60 min of endurance running performance in moderately trained men. Br. J. Sports Med. 2010, 44, 516-521. [CrossRef] [PubMed]

29. Johns, M. The Assessment of 'Sleepiness' in Human Drug Trials: A New Perspective. Curr. Psychopharmacol. 2019, 8, 5-26. [CrossRef] 
30. Buysse, D.J.; Reynolds, C.F., III; Monk, T.H.; Berman, S.R.; Kupfer, D.J. The Pittsburgh Sleep Quality Index: A new instrument for psychiatric practice and research. Psychiatry Res. 1989, 28, 193-213. [CrossRef]

31. Moghaddam, J.F.; Nakhaee, N.; Sheibani, V.; Garrusi, B.; Amirkafi, A. Reliability and validity of the Persian version of the Pittsburgh Sleep Quality Index (PSQI-P). Sleep Breath 2012, 16, 79-82. [CrossRef]

32. Faul, F.; Erdfelder, E.; Lang, A.G.; Buchner, A. G* Power 3: A flexible statistical power analysis program for the social, behavioral and biomedical sciences. Behav. Res. Methods 2007, 39, 175-191. [CrossRef] [PubMed]

33. Beck, T.W. The importance of a priori sample size estimation in strength and conditioning research. J. Strength Cond. Res. 2013, 27, 2323-2337. [CrossRef]

34. Cohn, J. Statistical Power Analysis for the Behavioral Sciences; Lawrence Earlbam Associate: Hills-dale, NJ, USA, 1988.

35. Cherif, A.; Roelands, B.; Meeusen, R.; Chamari, K. Effects of intermittent fasting, caloric restriction, and Ramadan intermittent fasting on cognitive performance at rest and during exercise in adults. Sports Med. 2016, 46, 35-47. [CrossRef] [PubMed]

36. Ali, M.R.; Amir, T. Effects of fasting on visual flicker fusion. Percept. Mot. Ski 1989, 69, 627-631. [CrossRef]

37. Dolu, N.; Yiiksek, A.; Sizer, A.; Alay, M. Arousal and continuous attention during Ramadan intermittent fasting. J. Basic Clin. Physiol. Pharm. 2007, 18, 315-322. [CrossRef]

38. El Moutawakil, B.; Hassounr, S.; Sibai, M.; Rafai, M.A.; Fabrigoule, C.; Slassi, I. N-10 Impact du jeûn du Ramadan sur les fonctions attentionnelles. Rev. Neurol. 2007, 163, 60. [CrossRef]

39. Bouhlel, E.; Shephard, R.J. Optimizing Physical Performance During Fasting and Dietary Restriction: Implications for Athletes and Sports Medicine; CRC Press: Boca Raton, FL, USA, 2015.

40. Lotfi, S.; Madani, M.; Abassi, A.; Tazi, A.; Boumahmaza, M.; Talbi, M. CNS activation, reaction time, blood pressure and heart rate variation during ramadan intermittent fasting and exercise. World J. Sport Sci. 2010, 3, 37-43.

41. Bouhlel, H.; Latiri, I.; Zarrrouk, N.; Bigard, X.; Shephard, R.; Tabka, Z.; Bouhlel, E. Effect of Ramadan observance and maximal exercise on simple and choice reaction times in trained men. Sci. Sports 2014, 29, 131-137. [CrossRef]

42. Venkatraman, V.; Chuah, Y.L.; Huettel, S.A.; Chee, M.W. Sleep deprivation elevates expectation of gains and attenuates response to losses following risky decisions. Sleep 2007, 30, 603-609. [CrossRef]

43. Roky, R.; Houti, I.; Moussamih, S.; Qotbi, S.; Aadil, N. Physiological and chronobiological changes during Ramadan intermittent fasting. Ann. Nutr. Metab. 2004, 48, 296-303. [CrossRef]

44. Zerguini, Y.; Kirkendall, D.; Junge, A.; Dvorak, J. Impact of Ramadan on physical performance in professional soccer players. Br. J. Sports Med. 2007, 41, 398-400. [CrossRef]

45. Herrera, C.P. Total sleep time in Muslim football players is reduced during Ramadan: A pilot study on the standardized assessment of subjective sleep-wake patterns in athletes. J. Sports Sci. 2012, 30 (Suppl. 1), S85-S91. [CrossRef] [PubMed]

46. Mo'ez Al-Islam, E.F.; Jahrami, H.A.; Alhayki, F.A.; Alkhawaja, N.A.; Ali, A.M.; Aljeeb, S.H.; Abdulghani, I.H.; BaHammam, A.S. Effect of diurnal fasting on sleep during Ramadan: A systematic review and meta-analysis. Sleep Breath 2019, 24, 771-782.

47. Qasrawi, S.O.; Pandi-Perumal, S.R.; BaHammam, A.S. The effect of intermittent fasting during Ramadan on sleep, sleepiness, cognitive function, and circadian rhythm. Sleep Breath 2017, 21, 577-586. [CrossRef] [PubMed]

48. Calder, A. Recovery strategies for sports performance. USOC Olymp. Coach E Mag. 2003, 15, 8-11.

49. Halson, S.L. Monitoring training load to understand fatigue in athletes. Sports Med. 2014, 44, 139-147. [CrossRef]

50. Singh, R.; Hwa, O.C.; Roy, J.; Jin, C.W.; Ismail, S.M.; Lan, M.F.; Hiong, L.L.; Aziz, A.R. Subjective perception of sports performance, training, sleep and dietary patterns of malaysian junior muslim athletes during ramadan intermittent fasting. Asian J. Sports Med. 2011, 2, 167. [CrossRef]

51. Pluijms, J.P.; Cañal-Bruland, R.; Kats, S.; Savelsbergh, G.J. Translating key methodological issues into technological advancements when running in-situ experiments in sports: An example from sailing. Int. J. Sports Sci. Coach. 2013, 8, 89-103. [CrossRef]

52. Williams, A.M.; Elliott, D. Anxiety, expertise, and visual search strategy in karate. J. Sport Exerc. Psychol. 1999, 21, 362-375. [CrossRef]

53. Mulè, A.; Galasso, L.; Castelli, L.; Condemi, V.; Bisconti, A.V.; Esposito, F.; Roveda, E.; Montaruli, A. Effect of chronotype on rating of perceived exertion in active young people. Sport Sci. Health 2020, 16, 331-336. [CrossRef]

54. Roveda, E.; Mulè, A.; Galasso, L.; Castelli, L.; Scurati, R.; Michielon, G.; Esposito, F.; Caumo, A.; Montaruli, A. Effect of chronotype on motor skills specific to soccer in adolescent players. Chronobiol. Int. 2020, 37, 552-563. [CrossRef] [PubMed]

55. Montaruli, A.; Castelli, L.; Galasso, L.; Mulè, A.; Bruno, E.; Esposito, F.; Caumo, A.; Roveda, E. Effect of chronotype on academic achievement in a sample of Italian University students. Chronobiol. Int. 2019, 36, 1482-1495. [CrossRef] [PubMed] 